\title{
Spinal Imaging Findings of Open Spinal Dysraphisms on Fetal and Postnatal MRI
}

\author{
(D) U.D. Nagaraj, (D) K.S. Bierbrauer, (D) C.B. Stevenson, (D).L. Peiro, DF.Y. Lim, (DB. Zhang, and (D) B.M. Kline-Fath
}

\begin{abstract}
BACKGROUND AND PURPOSE: Fetal MRI has become a valuable tool in the evaluation of open spinal dysraphisms making studies comparing prenatal and postnatal MRI findings increasingly important. Our aim was to determine the accuracy of predicting the level of the spinal dysraphic defect of open spinal dysraphisms on fetal MR imaging and to report additional findings observed when comparing fetal and postnatal MR imaging of the spine in this population.
\end{abstract}

MATERIALS AND METHODS: A single-center retrospective analysis was performed of fetal MRIs with open spinal dysraphisms from 2004 through 2016 with available diagnostic postnatal spine MR imaging. Images were reviewed by 2 board-certified fellowship-trained pediatric neuroradiologists. Corresponding clinical/operative reports were reviewed.

RESULTS: One hundred nineteen fetal MRIs of open spinal dysraphisms were included. The level of the osseous defect between fetal and postnatal MR imaging was concordant in 42.9\% (51/119) of cases and was 1 level different in 39\% (47/119) of cases. On postnatal MR imaging, type II split cord malformation was seen in $8.4 \%$ (10/119) of cases, with only 50\% (5/10) of these cases identified prospectively on fetal MR imaging. Syrinx was noted in 3\% (4/119) of prenatal studies, all cervical, all confirmed on postnatal MR imaging.

CONCLUSIONS: Fetal MR imaging is accurate in detecting the level of the spinal dysraphic defect, which has an impact on prenatal counseling, neurologic outcomes, and eligibility for fetal surgery. In addition, fetal MR imaging is limited in its ability to detect split cord malformations in patients with open spinal dysraphisms. Although rare, fetal MR imaging has a high specificity for detection of cervical spinal cord syrinx.

ABBREVIATION: OSD = open spinal dysraphism

$F^{-1}$ tal MR imaging has been well-established as a powerful tool in the prenatal evaluation of the neuroaxis and continues to play an increasing role in prenatal diagnosis, management, and counseling. ${ }^{1,2}$ The Management of Myelomeningocele (MOMS) trial remains the sentinel work driving more centers across the country to offer prenatal repair of open spinal dysraphisms (OSDs),

Received April 1, 2018; accepted after revision June 25.

From the Department of Radiology and Medical Imaging (U.D.N., B.Z., B.M.K.-F.) Department of Pediatric Neurosurgery (K.S.B., C.B.S.), Department of Pediatric Sur gery (J.L.P., F.Y.L.), and Department of Biostatistics and Epidemiology (B.Z.),University of Cincinnati College of Medicine, Cincinnati Children's Hospital Medical Center; Cincinnati, Ohio.

Preliminary results previously presented as an oral presentation at: Annual Meeting of the American Society of Neuroradiology and the Symposium of the ASNR Foundation, June 2-7, 2018; Vancouver, British Columbia, Canada.

Please address correspondence to Usha D. Nagaraj, MD, University of Cincinnat College of Medicine, Department of Radiology and Medical Imaging, Cincinnati Children's Hospital Medical Center, 3333 Burnet Ave, Cincinnati, OH 45229-3026; e-mail: usha.nagaraj@cchmc.org; @CincyKidsRad

http://dx.doi.org/10.3174/ajnr.A5760 for which fetal MR imaging has become an essential part of the workup, guiding clinical management. ${ }^{3,4}$

Despite the heavy reliance on fetal MR imaging in the evaluation of open spinal dysraphisms and its use in the selection of candidates for fetal surgery, the scientific literature examining MR imaging of the fetal spine is limited, and there are very few studies that compare pre- and postnatal MR imaging findings. ${ }^{5-8}$ Determining the level of the defect is a key component of the inclusion criteria for fetal surgery and provides valuable information for prognosis and prenatal counseling. ${ }^{8,9}$

Our aim was to determine the accuracy of predicting the upper level of the spinal dysraphic defect of open spinal dysraphisms on fetal MR imaging and to report additional findings observed when comparing fetal and postnatal MR imaging of the spine.

\section{MATERIALS AND METHODS Study Design}

This study is a single-center, retrospective chart review. The case list was manually compiled from all the fetal MRIs performed at Cincinnati Children's Hospital Medical Center in Cincinnati, 
Ohio, between 2004 and 2016. Inclusion criteria were fetuses with diagnostic-quality fetal MRIs for OSD (either myelomeningocele or myelocele). ${ }^{10}$ Only fetuses with adequate available postnatal neuroimaging and clinical/neurosurgical follow-up were included. Criteria for adequate postnatal neuroimaging for this study included a diagnostic-quality MR imaging of the spine within the first 3 months of life, which was used as the gold standard in this study. Determination of diagnostic-quality imaging was made at the neuroradiologists' discretion. The images were viewed in the PACS. A chart review was performed to obtain relevant clinical data. This study was compliant with the Health Insurance Portability and Accountability Act and was approved by the institutional review board. The requirement for informed consent was waived.

\section{Scanning Parameters}

All fetuses included in our study were scanned prenatally on a 1.5T magnet at Cincinnati Children's Hospital Medical Center by using a Ingenia 1.5T (Philips Healthcare, Best, the Netherlands) or 1.5T Signa HDxt (GE Healthcare, Milwaukee, Wisconsin) system. The spinal dysraphism protocol included axial, sagittal, and coronal T2-single-shot FSE and balanced fast-field echo/FIESTA images of the neuroaxis at 3- to 4-mm slice thickness with no skip. Although this imaging protocol did not change during the study period, the TR and TE varied on each scanner and were changed at times of scanner upgrades to optimize image quality. At least 2 stacks of images in each plane were obtained to the radiologists' satisfaction. The smallest FOV possible was used. Postnatal MR imaging was performed on 1 of 6 inpatient clinical magnets with evolving imaging protocols across the years. By 2014, T2-singleshot FSE images were largely replaced by T2-FSE images, and by 2015, true fast imaging with steady-state precession/FIESTA images became a routine part of the postnatal spinal dysraphism protocol.

\section{Image Interpretation}

All images were reviewed by 2 board-certified radiologists (U.D.N., B.M.K.-F.), both with added qualifications in pediatric radiology and fellowship training in pediatric neuroradiology. The readers were blinded to the pre- and postnatal imaging findings and reported fetal sonographic findings at the time of interpretation. Differences were resolved by consensus.

Multiple imaging parameters were evaluated on fetal MR imaging of the spine. The superior level of the spinal dysraphic defect was determined on fetal MR imaging by establishing the most caudal spinal hyperintense disc space as L5-S1 and the lowest horizontal vertebral body as L5 and by counting vertebral bodies superior to the highest level of the absence of the posterior elements at the bone/skin defect. ${ }^{8}$ On postnatal MR imaging, the defect level was determined superior to inferior by examining the entire spine, with the odontoid being labeled $\mathrm{C} 2$ and assuming 7 cervical vertebral bodies and 12 thoracic vertebral bodies. The presence of an arachnoid cyst, defined as an intradural extramedullary thin-walled CSF-intensity fluid collection, was documented. The presence or absence of a measurable postoperative fluid collection, visible spinal cord syrinx, or type II split cord malformation was also documented. ${ }^{11}$
Table 1: Summary of cohort

\begin{tabular}{lc}
\hline \multicolumn{1}{c}{ Characteristics } & Data $(N=119)$ \\
\hline Sex & \\
Male & $43.7 \%(52 / 119)$ \\
Female & $56.3 \%(67 / 119)$ \\
Average GA at fetal MRI (wk) & $23.9 \pm 3.6$ \\
Fetal Chiari grade & \\
III & $81.5 \%(97 / 119)$ \\
II & $11.8 \%(14 / 119)$ \\
I & $6.7 \%(8 / 119)$ \\
Clubfoot & \\
None & $76.5 \%(91 / 119)$ \\
Unilateral & $5.9 \%(7 / 119)$ \\
Bilateral & $17.6 \%(21 / 119)$ \\
In utero vs postnatal repair & \\
Open in utero repair & $31.9 \%(38 / 119)$ \\
Postnatal repair & $68.1 \%(81 / 119)$ \\
Average age at postnatal spine MRI (days) & $19.9 \pm 20.2$ \\
\hline
\end{tabular}

Note:-GA indicates gestational age.

Additional intracranial findings on fetal MR imaging were recorded, including the degree of posterior fossa hindbrain herniation by Chiari grades $1-3$, with grade 1 having a patent fourth ventricle and cisterna magna, grade 2 having effacement of the fourth ventricle with a patent cisterna magna, and grade 3 having effacement of both the cisterna magna and the fourth ventricle. ${ }^{12,13}$ Lateral ventricular size, by measuring the transverse atrial diameter on an axial or coronal image, and third ventricular size, by measuring the transverse diameter on a coronal image, were also recorded. ${ }^{13-15}$ The presence or absence of a clubfoot and, when present, whether it was unilateral or bilateral were also routinely reported. ${ }^{16}$

\section{Statistical Analysis}

Descriptive analyses were performed to demonstrate the distribution of the imaging findings. Continuous variables were presented as means \pm SDs, and categoric variables were presented as number (percentage). A 2-sample $t$ test or 1-way ANOVA was used to detect the differences in continuous variables among different groups. The correlation among categoric variables was assessed by the $\chi^{2}$ or Fisher exact test when appropriate. All analyses were performed using the Statistical Analysis System, Version 9.4 (SAS Institute, Cary, North Carolina). A $P$ value $<.05$ was considered statistically significant.

\section{RESULTS}

\section{Description of Cohort}

A total of 119 fetuses (52 male, 67 female) met the criteria and were included in this analysis. The average gestational age at fetal MR imaging was $23.9 \pm 3.6$ weeks in the cohort as a whole. While $31.9 \%(38 / 119)$ of fetuses underwent open in utero repair of OSD, the remaining $68.1 \%(81 / 119)$ underwent postnatal repair. The average age at postnatal spine MR imaging was $19.9 \pm 20.2$ days. These and other descriptors of the cohort are summarized in Table 1.

\section{Imaging Findings}

Level of the Defect. The upper level of the osseous defect on fetal MR imaging ranged from as high as T10 to as low as S3. Most patients had lumbar defects, $68.9 \%$ (82/119), with the largest per- 


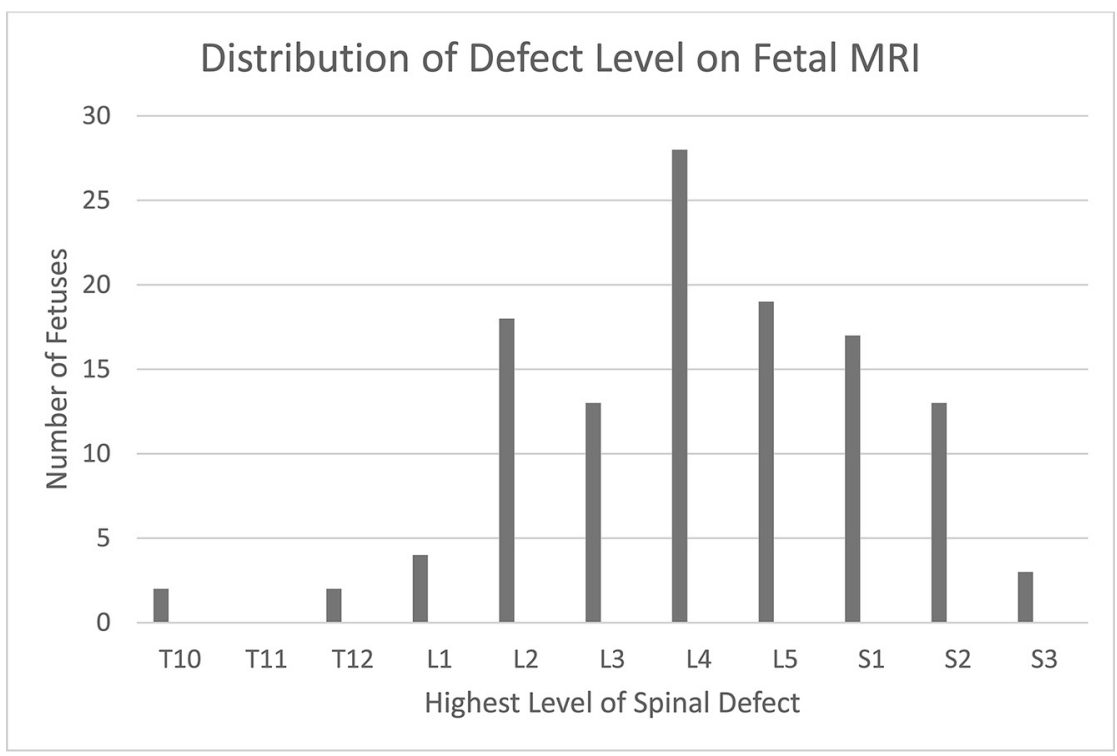

FIG 1. Distribution of defect levels on fetal MR imaging.
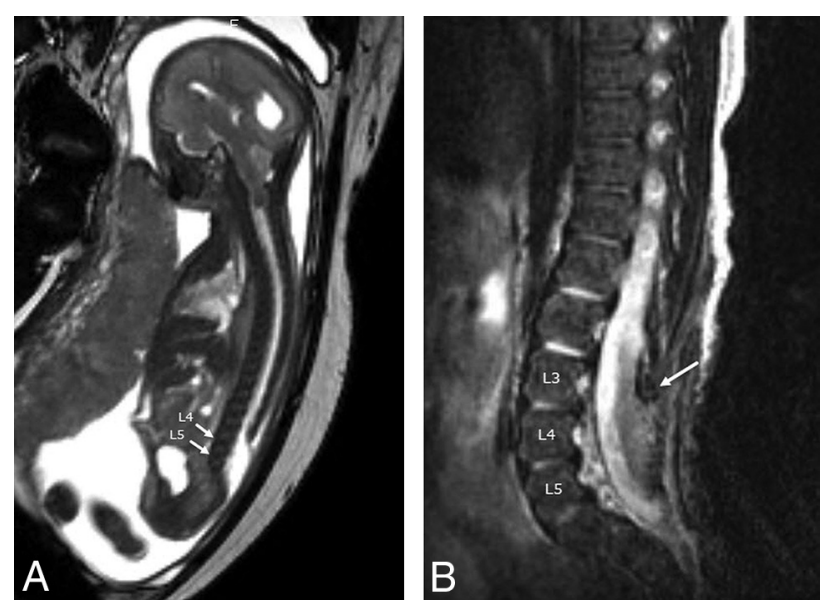

FIG 2. Sagittal balanced fast-field echo/FIESTA image from fetal MR imaging at 24 weeks' 5 days' gestational age $(A)$ demonstrates findings of a lumbosacral myelomeningocele with the upper level of the spinal dysraphic defect beginning at L4. Sagittal T2-FSE image from postnatal MR imaging of the spine in the same patient at 20 days of age $(B)$ shows postoperative changes from OSD closure, with the upper level of the defect again beginning at L4 (same level), with L3 having an intact neural arch (arrow).

centage being at L4 $(23.5 \%, 28 / 119) ; 13.4 \%$ (16/119) had a defect at S2 or lower (Fig 1); 42.9\% (51/119) had the same defect level interpreted on postnatal spinal MR imaging compared with the fetal MR imaging; 39.5\% (47/119) were 1-level discrepant; $11.8 \%$ (14/119) were discrepant at 2 levels; and 5.9\% (7/119) were 3-levels discrepant (Fig 2). Of the discrepant levels, 42.6\% (29/68) were interpreted as lower than on the postnatal MR imaging and $57.4 \%$ (39/68) were higher on postnatal MR imaging; 13.4\% (16/119) of patients were interpreted as having a defect at S2 or S3, which would preclude them from fetal surgery; $62.5 \%$ (10/16) of these patients were concordant to the exact level on postnatal MR imaging and 25\% (4/16) were higher and $12.5 \%$ (2/16) were lower.

There was a significant correlation between the level of the defect and lateral ventricular size $(P=.001)$ on fetal MR imaging, with a higher defect level correlating with larger lateral ventricular repair (Table 3 ).

\section{DISCUSSION} MR imaging. size. There was no significant correlation between defect level and Chiari grade, third ventricular size, and the presence of a clubfoot (Table 2).

Split Cord Malformation and Syrinx. On fetal MR imaging, the possibility of a type II split cord malformation was raised in 13\% (16/119) of patients; however, only $31 \%(5 / 16)$ were confirmed on postnatal MR imaging. On postnatal MR imaging, split cord malformation was seen in $8.4 \%(10 / 119)$ of cases, with only of 50\% (5/10) of these cases identified prospectively on fetal MR imaging (Fig 3). Syrinx was noted in 3\% (4/119) of prenatal studies, all cervical, all confirmed on postnatal MR imaging; however, fetal MR imaging was performed after the second trimester in $75 \%(3 / 4)$ of these patients (Fig 4).

Postnatal Spine MR Imaging. Postnatal MR imaging was performed in all patients at an average age of $19.9 \pm 20.2$ days; $31.9 \%$ (38/119) of patients had undergone prenatal repair; 65.5\% (78/ 119) had undergone postnatal repair; $2.5 \%$ (3/119) of patients had spine MR imaging before postnatal repair; 39\% (47/119) of postnatal spine MRIs had evidence of spinal cord syrinx, and of these subjects $29.8 \%$ (14/47) had undergone prenatal repair, 68\% (32/47) had undergone postnatal repair, and 2\% (1/47) was imaged before postnatal repair. Measurable postoperative extraspinal fluid collections were seen in $32.8 \%$ (38/116) of postnatal spine MRIs, $5.3 \%$ (2/38) of these patients had undergone prenatal repair; $3.4 \%$ (4/119) of patients had intraspinal arachnoid cysts on postnatal spine MR imaging, 50\% (2/4) of whom had undergone prenatal repair; $36.2 \%(42 / 116)$ of patients did not have any evidence of syrinx, fluid collection, or arachnoid cyst on postnatal spine MR imaging, 50\% (21/42) of whom had undergone prenatal

We describe our experience with spine imaging findings of OSD on fetal and postnatal MR imaging and have made several observations: Concordance within 1 level of the osseous defect was seen in $82 \%$ of patients between pre- and postnatal MR imaging. There was a significant correlation between the level of the defect and lateral ventricular size ( $p=0.001)$, with a higher defect level correlating with larger lateral ventricular size. Fetal MR imaging was limited in its ability to identify split cord malformation in this population. Finally, syrinx was noted in only $3 \%$ of prenatal studies; however, all were cervical and all were confirmed on postnatal

Existing literature describing the accuracy of prenatal level assignments of the OSD defect, defined as the highest open posterior vertebral arch, is quite limited. One series described equal accuracy of fetal sonography and fetal MR imaging in level assignments for myelomeningocele compared with postnatal imaging, though it was observed that prenatally assigned levels using either 


\begin{tabular}{lcccc}
\hline & $\begin{array}{c}\text { Chiari } \\
\text { Grade (I-III) }\end{array}$ & $\begin{array}{c}\text { Lateral Ventricular } \\
\text { Size (mm) }\end{array}$ & $\begin{array}{c}\text { Third Ventricular } \\
\text { Size (mm) }\end{array}$ & $\begin{array}{c}\text { Clubfoot (Absent, } \\
\text { Unilateral, Bilateral) }\end{array}$ \\
\hline Level of spinal dysraphic defect & $P=.07$ & $P=.001$ & $P=.86$ & $P=.3$ \\
\hline
\end{tabular}
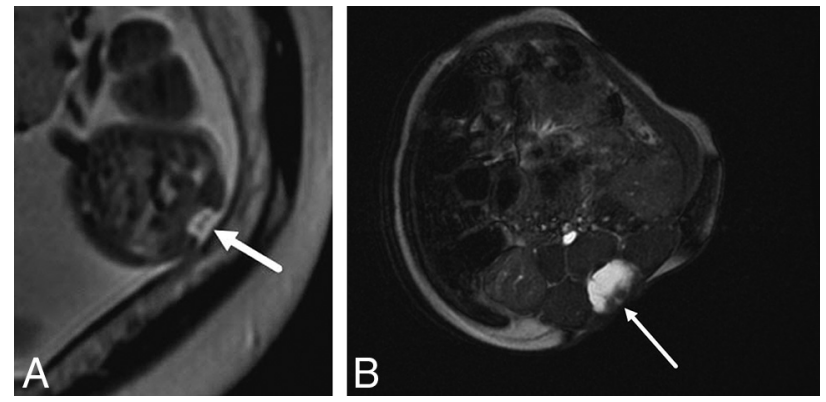

FIG 3. Axial T2-single-shot FSE image through a 23 weeks' 3 days' gestational age fetus $(A)$ with a myelocele demonstrates splitting of the neural placode (arrow), consistent with a type II split cord malformation. Axial balanced fast-field echo/FIESTA image from postnatal spine MR imaging of the same patient at 4 weeks of age confirms the prenatal findings of split cord malformation status post repair (arrow).
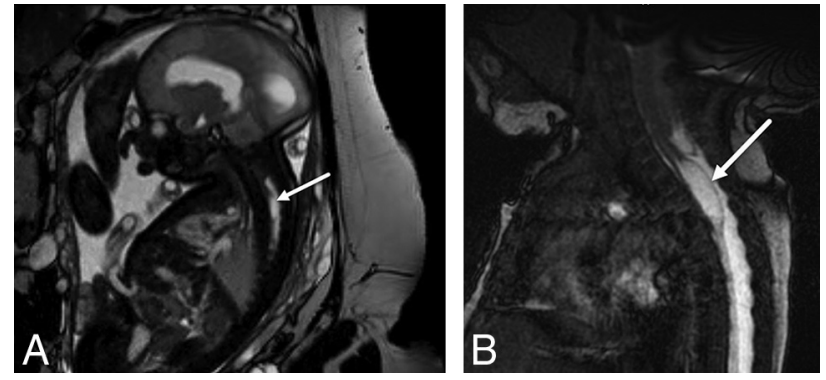

FIG 4. Sagittal balanced fast-field echo/FIESTA image from fetal MR imaging at 32 weeks' gestational age $(A)$ shows a spinal cord syrinx in the cervicothoracic spine (arrow). Sagittal balanced fast-field echo/ FIESTA image from postnatal spine MR imaging in the same patient at 1 month of age $(B)$ shows persistence of the syrinx (arrow).

technique may vary by $\geq 2$ segments from the postnatal assigned levels in at least $20 \%$ of cases. ${ }^{17,18}$ Our study has similar findings and adds to the literature our experience in a larger cohort in which we found that the exact level of concordance between fetal and postnatal MR imaging was only 42.9\% (51/119) and was within 1 level of concordance in $82 \%$ (98/119) of patients. The reasons are multifactorial and may, in part, relate to the very small size of the fetus being imaged, making it challenging to resolve millimetric-sized landmarks, in addition to the lack of ability to resolve the disc spaces in the entire spine for accurate vertebral body counting on fetal MR imaging. In addition, determination of the defect level may be compromised postnatally by the postoperative changes, making a dysraphic defect at the surgical margin versus scar tissue challenging to differentiate. Also, normal anatomic variations in vertebral body counting, such as the presence of 6 lumbarized vertebral bodies, were not taken in to account on fetal MR imaging. This information is important, particularly when selecting candidates for fetal surgery because fetuses with a defect lower than S1 do not meet the selection criteria per the MOMS trial. ${ }^{19}$

There is literature describing the correlation of the prenatal defect level with the postnatal neurologic function, making the identification of the defect level prenatally of potential importance in counseling. ${ }^{20}$ Despite previous sonographic literature describing no significant relationship between defect level and ventricular size, our study illustrates how a higher spinal defect is associated with larger lateral ventricular size on fetal MR imaging in a larger sample size. ${ }^{21}$ This finding is of potential clinical significance because larger ventricles on prenatal imaging have been shown to be associated with an increased need for shunting in those undergoing fetal surgery. ${ }^{22}$ On the contrary, despite previous literature describing a higher incidence of foot deformity with higher lesion levels, we did not observe a significant correlation between the fetal spinal defect level and the presence of clubfoot deformity in our cohort. ${ }^{23}$ This finding suggests that the pathophysiology of this disease process is complex and influenced by multiple factors, and further studies may be helpful in improving prenatal counseling. Our study also adds the observation that there was no significant correlation between defect level and Chiari grade or third ventricle size.

Prenatal diagnosis of split cord malformation, also known as diastematomyelia, has been described in a few isolated cases; however, the diagnostic reliability of fetal MR imaging in a larger population is still unclear. ${ }^{24,25}$ Our series adds to the literature by demonstrating a relatively limited ability of fetal MR imaging to identify type II split cord malformation. The lack of our ability to consistently identify split cord malformation prospectively on fetal MR imaging can likely be explained by the very small size of the fetus being imaged. However, it is less clear why cases in which split cord malformation was questioned prenatally were not confirmed on postnatal MR imaging. It is possible that clumped nerve roots from the ventral neural placode or a prominent anterior median fissure of the spinal cord was mistaken for split cord malformation on fetal MR imaging. ${ }^{26,27}$ Another possibility is that postoperative changes from OSD closure obscure the underlying split cord malformation on postnatal MR imaging. While the association between type II split cord malformation and open spinal dysraphisms is known and does not preclude fetal surgery, knowing that our ability to diagnose this prenatally is limited may be helpful in counseling. There are notable clinical implications of split cord malformation in this population: Not only do these patients often require more extensive surgical untethering early in life or at the time of primary repair, but they are also at increased risk of tethered cord syndrome and progressive scoliosis postnatally. ${ }^{28-31}$

Our study also adds to the literature a description of imaging findings on postnatal spine MR imaging in patients with OSD after both prenatal and postnatal repair. Most notably, we observed that syrinx can be seen in association with open spinal dysraphism on fetal MR imaging. ${ }^{32}$ We describe its incidence in a relatively large sample of fetuses with open spinal dysraphism $(3.4 \%, 4 / 119)$ and demonstrate a high specificity of fetal MR imaging, particularly in the third trimester, because all fetuses with a prenatally diagnosed syrinx in our series had the same findings on 


\begin{tabular}{|c|c|c|c|c|}
\hline & $\begin{array}{l}\text { Percentage of } \\
\text { Total }(N=119)\end{array}$ & $\begin{array}{l}\text { Percentage of } \\
\text { Prenatal Repair } \\
\text { Group ( } n=38 \text { ) }\end{array}$ & $\begin{array}{l}\text { Percentage of } \\
\text { Postnatal Repair } \\
\text { Group }(n=78)\end{array}$ & $P$ Value \\
\hline Extraspinal postoperative fluid collection & $32.8 \%(38 / 116)$ & $5.3 \%(2 / 38)$ & $46.2 \%(36 / 78)$ & $P<.001$ \\
\hline Arachnoid cyst & $3.4 \%(4 / 119)$ & $5.3 \%(2 / 38)$ & $2.6 \%(2 / 78)$ & $P=.46$ \\
\hline Syrinx & $39.5 \%(47 / 119)$ & $36.8 \%(14 / 38)$ & $41 \%(32 / 78)$ & $P=.67$ \\
\hline No syrinx, no fluid collection, and no arachnoid cyst & $36.2 \%(42 / 116)$ & $55.3 \%(21 / 38)$ & $26.9 \%(21 / 78)$ & $P=.003$ \\
\hline
\end{tabular}

postnatal MR imaging. The increased incidence of syrinx on postnatal MR imaging $(39.5 \%, 47 / 119)$ compared with prenatal MR imaging $(3.4 \%, 4 / 119)$ is likely explained by ongoing associated abnormalities of CSF flow dynamics in this population, including hindbrain herniation, hydrocephalus, and tethered cord rather than a missed congenital syrinx. ${ }^{33}$ Although postoperative fluid collections were more frequently seen in the postnatal repair group $(46.2 \%, 36 / 78)$ compared with the prenatal repair group $(5.3 \%, 2 / 38)$, this finding can likely be explained by the relative time of imaging after the operation. We also add our observed incidence of intraspinal arachnoid cysts on postnatal spine MR imaging in this patient population $(3.4 \%, 4 / 119)$, which was seen equally in those that underwent prenatal versus postnatal repair.

Our study has some limitations. First, this is a retrospective study, which limits its internal validity. Also, given that this is a single-institution study performed within a certain timeframe, its external validity may be limited as well. Along those same lines, this study is also likely subject to some degree of selection bias because the data were collected from one of the largest referral centers in the country for prenatal repair of open spinal dysraphisms. Also, given that imaging studies were acquired during a 12-year period on multiple different clinical magnets with periodic upgrades, the heterogeneity of scanning parameters may affect our results as well. In clinical practice, sonography is often used in conjunction with fetal MR imaging to determine the defect level of an open spinal dysraphism, and in our practice, we emphasize the sonographic findings for defect level in fetal counseling because some believe that sonography can better delineate the osseous structures of the fetal spine than fetal MR imaging. ${ }^{34}$ However, given that sonography is highly operator-dependent, which is problematic in clinical practice and in the context of a retrospective analysis, studies in fetal MR imaging of the spine are becoming increasingly important.

\section{CONCLUSIONS}

We describe several observations at our institution on fetal and postnatal MR imaging of the spine in patients with OSD and add to the existing literature several important findings. First, fetal MR imaging is accurate in detecting the level of the dysraphic defect, which has an impact on prenatal counseling, neurologic outcomes, and eligibility for fetal surgery. We also found that a higher defect level correlated with increased fetal ventricular size. Second, we describe additional findings of associated split cord malformation and spinal cord syrinx on fetal MR imaging in this population. Fetal MR imaging was limited in its ability to identify split cord malformation in our series. Finally, although cervical spinal cord syrinx is uncommon, we found fetal MR imaging to be a useful tool for detecting it in patients with OSD.
Disclosures: Usha D. Nagaraj—UNRELATED: Royalties: Elsevier, Comments: for chapters written for a diagnostic imaging textbook. Karin S. Bierbrauer-UNRELATED: Board Membership: Spina Bifida Coalition of Cincinnati. Beth M. Kline-FathUNRELATED: Payment for Lectures Including Service on Speakers Bureaus: lecture to radiologist at Mayo Clinic,* *Money paid to the institution.

\section{REFERENCES}

1. Glenn OA, Barkovich J. Magnetic resonance imaging of the fetal brain and spine: an increasingly important tool in prenatal diagnosis: Part 2. AJNR Am J Neuroradiol 2006;27:1807-14 Medline

2. Glenn OA, Barkovich AJ. Magnetic resonance imaging of the fetal brain and spine: an increasingly important tool in prenatal diagnosis-Part 1. AJNR Am J Neuroradiol 2006;27:1604-11 Medline

3. Adzick NS, Thom EA, Spong CY, et al. A randomized trial of prenatal versus postnatal repair of myelomeningocele. N Engl J Med 2011; 364:993-1004 CrossRef Medline

4. Committee on Obstetric Practice Society for Maternal-Fetal Medicine. Maternal-fetal surgery for myelomeningocele. 2017;130:164-67 Medline

5. Husler MR, Danzer E, Johnson MP, et al. Prenatal diagnosis and postnatal outcome of fetal spinal defects without Arnold-Chiari II malformation. Prenat Diagn 2009;29:1050-57.

6. Huang YL, Wong AM, Liu HL, et al. Fetal magnetic resonance imaging of normal spinal cord: evaluating cord visualization and conus medullaris position by T2-weighted sequences. Biomed J 2014; 37:232-36 CrossRef Medline

7. Duczkowska A, Bekiesinska-Figatowska M, Herman-Sucharska I, et al. Magnetic resonance imaging in the evaluation of the fetal spinal canal contents. Brain Dev 2011;33:10-20 CrossRef Medline

8. Chao TT, Dashe JS, Adams RC, et al. Fetal spine findings on MRI and associated outcomes in children with open neural tube defects. AJR Am J Roentgenol 2011;197:956-61 CrossRef Medline

9. Sutton LN. Fetal surgery for neural tube defects. Best Pract Res Clin Obstet Gynaecol 2008;22:175-88 CrossRef Medline

10. Tortori-Donati P, Rossi A, Cama A. Spinal dysraphism: a review of neuroradiological features with embryological correlations and proposal for a new classification. Neuroradiology 2000;42:471-91 CrossRef Medline

11. Pang D, Dias M, Ahab-Barmada M. Split cord malformation, Part I: a unified theory of embryogenesis for double spinal cord malformations. Neurosurgery 1992;31:451-80 CrossRef Medline

12. Sutton LN, Adzick NS, Bilaniuk LT, et al. Improvement in hindbrain herniation demonstrated by serial fetal magnetic resonance imaging following fetal surgery for myelomeningocele. JAMA 1999;282: 1826-31 Medline

13. Nagaraj UD, Bierbrauer KS, Zhang B, et al. Hindbrain herniation in Chiari II malformation on fetal and postnatal MRI. AJNR Am JNeuroradiol 2017;38:1031-36 CrossRef Medline

14. Levine D, Trop I, Mehta TS, et al. MR imaging appearance of fetal cerebral ventricular morphology. Radiology 2002;223:652-60 CrossRef Medline

15. Garel C, Alberti C. Coronal measurement of the fetal lateral ventricles: comparison between ultrasonography and magnetic resonance imaging. Ultrasound Obstet Gynecol 2006;27:23-27 CrossRef Medline

16. Servaes S, Hernandez A, Gonzalez L, et al. Fetal MRI of clubfoot associated with myelomeningocele. Pediatr Radiol 2010;40:187479. CrossRef Medline

17. McEwing RL, Pretorius DH, James HE, et al. Prenatal assignation of lesion levels in neural tube defects by using ultrasonography: case 
report and review of the literature. J Neurosurg 2005;102(2 Suppl): 248-51 CrossRef Medline

18. Aaronson OS, Hernanz-Schulman M, Bruner JP, et al. Myelomeningocele: prenatal evaluation-comparison between transabdominal US and MR imaging. Radiology 2003;227:839-43 CrossRef Medline

19. Adzick NS. Fetal surgery for myelomeningocele: trials and tribulations-Isabella Forshall Lecture. J Pediatr Surg 2012;47: 273-81 CrossRef Medline

20. Carreras E, Maroto A, Illescas T, et al. Prenatal ultrasound evaluation of segmental level of neurological lesion in fetuses with myelomeningocele: development of a new technique. Ultrasound Obstet Gynecol 2016;47:162-67 CrossRef Medline

21. Babcook CJ, Drake CM, Goldstein RB. Spinal level of fetal myelomeningocele: does it influence ventricular size? AJR Am J Roentgenol 1997;169:207-10 CrossRef Medline

22. Tulipan N, Wellons J, Thom EA, et al; MOMS Investigators. Prenatal surgery for myelomeningocele and the need for cerebrospinal fluid shunt placement. J Neurosurg Pediatr 2015;16:613-20 CrossRef Medline

23. Gunay H, Sozbilen MC, Gurbuz Y, et al. Incidence and type of foot deformities in patients with spina bifida according to level of lesion. Childs Nerv Syst 2016;32:315-19 CrossRef Medline

24. Sonigo-Cohen P, Schmit P, Zerah M, et al. Prenatal diagnosis of diastematomyelia. Childs Nerv Syst 2003;19:555-60 CrossRef Medline

25. Kutuk MS, Ozgun MT, Tas M, et al. Prenatal diagnosis of split cord malformation by ultrasound and fetal magnetic resonance imaging: case report and review of the literature. Childs Nerv Syst 2012;28:2169-72 CrossRef Medline
26. Rufener SL, Ibrahim M, Raybaud CA, et al. Congenital spine and spinal cord malformations: pictorial review. AJR Am J Roentgenol 2010;194(3 Suppl):26-37 CrossRef Medline

27. Tomsick TA, Peak E, Wang L. Fluid-signal structures in the cervical spinal cord on MRI: anterior median fissure versus central canal. AJNR Am J Neuroradiol 2017;38:840-45 CrossRef Medline

28. Higashida T, Sasano M, Sato H, et al. Myelomeningocele associated with split cord malformation type I: three case reports. Neurol Med Chir (Tokyo) 2010;50:426-30 Medline

29. Borkar SA, Mahapatra A. Split cord malformations: a two years experience at AIIMS. Asian J Neurosurg 2012;7:56-60 CrossRef Medline

30. Ansari S, Nejat F, Yazdani S, et al. Split cord malformation associated with myelomeningocele. J Neurosurg 2007;107(4 Suppl): 281-85 CrossRef Medline

31. Iskandar B, Mclaughlin C, Oakes W. Split cord malformations in myelomeningocele patients. Br J Neurosurg 2000;14:200-03 CrossRef Medline

32. Bixenmann B, Kline-Fath BM, Bierbrauer KS, et al. Prenatal and postnatal evaluation for syringomyelia in patients with spinal dysraphism. J Neurosurg Pediatr 2014;14:316-21 CrossRef Medline

33. Levine DN. The pathogenesis of syringomyelia associated with lesions at the foramen magnum: a critical review of existing theories and proposal of a new hypothesis. J Neurol Sci 2004;220:3-21 CrossRef Medline

34. Coleman BG, Langer JE, Horii SC. The diagnostic features of spina bifida: the role of ultrasound. Fetal Diagn Ther 2015;37: 179-96 CrossRef Medline 